NASZA DERMATOLOGIA Online

OUR DERMATOLOGY Online

Source of Support:

Nil

Competing Interests:

None

\section{LITIGATION AGAINST DERMATOSURGEONS AND COSMETOLOGISTS AND CONSUMER PROTECTION ACT}

\author{
Neerja Puri ${ }^{1}$, Ashutosh Talwar ${ }^{2}$ \\ ${ }^{1}$ Consultant Dermatologist, Punjab Health Systems Corporation, Punjab, India \\ ${ }^{2}$ Consultant Surgeon, Punjab Health Systems Corporation, Punjab, India
}

Corresponding author: Dr. Neerja Puri

neerjaashu@rediffmail.com

\begin{abstract}
The concept of beauty has acquired new dimensions due to the increasing awareness in general public about the aesthetic procedures. The problems between the patient and the cosmetologists arise when the patients expectations become very high and unrealistic. The classical concept of doctor - patient relationship born in the golden days of family physicians has undergone drastic change due to dramatic advancement in medical technology, availability of sophisticated imaging system, high tech electronics and preponderance of new diseases. However, the accountability of the doctors under the law of professional negligence has emerged as a debatable issue among the medical fraternity all over the country after the enactment of the consumer protection act, 1986, which has not only changed the law of medical negligencel, but created an inexpensive and speedy remedy against medical malpractice.
\end{abstract}

Key words: dematosurgeon; consumer protection act; negligence; medical insurance; compensation; cosmetologist; malpractice

\section{Introduction}

The dermatosurgeons and cosmetologists owe duty of care towards their patients. Failure to show due care or skill in medical treatment resulting in death, injury or pain of the patient gives rise to a cause of action in negligence [1]. A charge of professional negligence against a cosmetic surgeon is serious. It stands on a difficult footing to a charge of negligence against the driver of a motor car.The consequences are far more serious. It affects his professional status and reputation. With the best will in the world, things sometimes go amiss in surgical operations or medical treatment. A dermatosurgeon is not to be held negligent simply because something goes wrong. He is only liable when he falls below the standard of a reasonably competent practitioner in his field so much so that his conduct may be deserving of censure or inexcusable. A dermatosurgeon or cosmetologist will be judged by the standard of an average practitioner of the class to which he belongs or holds himself out to belong.

Failure to exercise due skill in diagnosis as a result of which wrong treatment is given, is held to amount to negligence [2]. A competent dermatosurgeon must know which case is beyond his skill. It is the bounden duty of the dermatosurgeon either to call in a more skillful person or to advise the removal of the patient to a place where skilled treatment is available. The dissatisfaction of the patients following dermatosurgery stems from inadequate communication between patient and the dermatosurgeon during the preoperative stage. The expected chances of success and failure, the risk and benefit of the procedure, the hazards and complications of the particular surgery should be explained to the patient before obtaining the consent for surgery. Under the general principles of tortuous liability the cosmetologist who caused injury or damage by negligence is bound to pay compensation. Taking a look at the above fallacies, it is advisable for a dermatosurgeon to get himself insured under the medical indemnity scheme of any of the national general insurance companies [3]. All this will help him to free from the heavy tensions of sudden financial load if any. Failure to obtain the history of the patient, may result in omission to make proper clinical examination leading to inappropriate therapy resulting in tragic end of the patient. The patient should be enquired about the drug history before the surgery because many drugs have serious complications if continued during the operation [4]. The duty of the dermatosurgeon is to observe the patient during postoperative stage in order to check abnormalities in pulse rate, blood pressure, respiration, urine output, temperature and consciousness level. It is important to monitor the fluid balance of the patient during postoperative period. The development of haematoma or wound infection is very common after emergency. Failure to diagnose and treat haematoma may contribute negligence [5]. 


\section{Discussion}

With the immense strides in technology health care has emerged as a profitable sector attracting investors from varied background in our country and the dermatosurgeons get to spend less and less time with their patients. Owing to lack of time,the dermatosurgeons and cosmetologists communicate adequately with the patients. As a result, the patient dissatisfaction is on the rise. Naturally, the dissatisfied patients are resorting to legal remedy [6]. Like other professionals the cosmetologists are liable to pay damages for their negligence under the law of torts. Unlike foreign countries the instances of award of damages in India are few and far between. The reason is obviously the low level of awareness of rights, the exorbitant court fees and the unending court procedures. A glance at the emerging scenario of the country indicates that our consumer courts are doing justice by giving adequate compensation to the genuinely affected patients and by dismissing the false and frivolous complaints with exemplary costs against committed cosmetologists. According to our apex court, a determination about deficiency in medical service is to be made by applying the same test as in an action for damages for medical negligence. One of the most important aspects of any profession is the degree of excellence, which a person practising that profession can give in his results. It is not at all expected that each and every dermatosurgeon would deliver the goods in the same expertise. There are so many aspects and factors that determine the relative competence of an individual in a group, vocation or a particular line of personalised and highly skilled practice. But what is important is that one acts, conducts himself and discharges his duties in such a manner as would be expected from a prudent contemporary in a similar situation having access to similar facilities. In a doctor - patient relationship, the patient is entitled to services from the doctor in such a degree of professional skill and expertise as would be expected from such a medical man of similar qualifications and standard [7]. In case the service availed is that from one who claims to be or is a qualified specialist, then the degree of skill required to be exercised is more. The dermatosurgeon must exercise the methods founded on scientific principles. It is pertinent to mention that the number of cases being filed before the redressal agencies under the consumer protection act relating to the cosmetologists are ever increasing. At the same time, in some cases the hospitals and nursing homes have filed complaints. The national consumer disputes redressal commission, which is sitting at New Delhi and the other state consumer disputes redressal commissions have delivered appreciable judgements on the basis of allegations made out in different cases in the light of provisions of the act [8]. These bodies are required to decide disputes while observing the fundamental principles of natural justice and have power to grant certain specific reliefs provided under section 14 of the act. In appropriate cases, the compensation or damages are also awarded. And it does not end here. There are penalties for non-compliance of the orders passed. So, you see the system, though simple on one hand, is doubtlessly effective and authoritative. Regarding 'Compensation', simply on hearing this word, spontaneously blood rushes in our bodies to claim the maximum, as it is apparently unearned. But it is not so. Damages, compensation and other incidental reliefs are based upon certain well-settled principles. There is compensation for other wrongs where loss suffered by party can be calculated in terms of money. The consumer protection act has also provided for granting of compensation or damages to an aggrieved consumer, but there is no table as such. Each case has its own peculiar circumstances and at best the quantum of penalty or fine etc is tried to be made commensurate with the degree of dereliction. Outflowing and incidental loss is also covered. Besides this, interest is also awarded and the costs of litigation may be awarded in addition to the above. Compensation to the aggrieved patients in consumer protection act is decided according to prescribed procedure. It is not at all inevitable that the court would grant a certain amount of money, because the same is claimed. The forums have to see first whether there was negligence or deficiency in service. Then, it is to be confirmed that the aforesaid negligence resulted in the loss to the patient. The nature and degree of loss is also vital i.e. the gravity of the injury caused and the span of period it would subsist. Furthermore, what implications would arise in the day to day life of the patient which includes financial loss, mental agony and social embarrassment etc. The age of the person, the source of income and the amount of income, further prospects in the career, the detriment caused due to the alleged disability, other diseases a patient is suffering from, history of chronic ailments and the concept of contributory negligence and extenuating circumstances which govern the formula to liquidate a sum of money as compensation. The expenses already incurred by the patient are also taken into account. In a nutshell, it depends on the peculiarity of facts and circumstances of each case and not by hard and fast rule. An error of judgement can be excused and reasonable degree of care and skill is expected but if the person professes to be specialist in the field, then a highest degree of skill is mooted. A dermatosurgeon charged with negligence can clear himself if he shows that he acted in accordance with general and approved practice [9]. It is not required in discharge of his duty of care that he should use highest degrees of skill, since each and every individual may never acquire the same. Even deviation from normal professional practice in peculiar and special circumstances is not necessarily evidence of negligence. As regards the standard of care required for the dermatosurgeon, it can be stated that a mistaken diagnosis is not necessarily a negligent diagnosis. A dermatosurgeon can only be held liable in this respect if the diagnosis is so palpably wrong as to prove negligence, that is to say if his mistake is of such a nature as to, imply an absence of reasonable skill and care on his part, regard being had to the ordinary level of skill in the profession [10].

\section{Conclusion}

In addition to the guidance given in the code of ethics, the certain other duties of a dermatosurgeon and cosmetologist should also be remembered :To use the necessary skill, care, judgement and attention in the treatment of his patients. He has full liberty to adopt any of the accepted theories of medicine or surgery in which he honestly believes. Also there is considerable scope for him in exercising his judgement and discretion, as medical science is not an exact science $[11,12]$. Dermatosurgeon must remember that he owes a duty towards his patients, whether there is any contract with the patient or not. 
As soon as a dermatosurgeon agrees to treat a patient, relationship is legally established, it neither guarantees a cure nor an assured improvement for the treatment given by him. To conclude, the dermatosurgeon should follow the IADVL approved standards of care in dermatosurgery and should not show any negligence while carrying out the procedures. Also, the cosmetic procedures should never be done free of cost, rather it should be charged heavily. This is to compensate for the harassment and mental agony a dermatologist has to face later in the court of law.

\section{REFERENCES}

1. Hobsley M: Medical Negligence. Anaesthesiol. 1990; 28:457-65. 2. Thomas TT, Elisa V: Professional negligence. Nat Med J India. 1987;34:461-7.

3. Rosen M, Horton JN: Medical negligence. Anaesth. 1990;27:2147.

4. Shenoy GG: Medicolegal forum - Anaesthesiology and law. Indian J Anaesth. 2005:49:20-3.

5. Francis CM: Autonomy and Informed Consent. Medical Ethics.

2 nd ed. New Delhi: Jaypee Brothers; 2004. p. 54-6.
6. Ravindran G, Kakam T, Lewin S, Pais P: Teaching Medical Ethics in a medical college in India. Nat Med J India. 1997;10:2889.

7. Gokani A: Doctors and patients. Indian Express 25 December 1995 p.8.

8. Entwistle VA, Sheldon TA, Sowden AJ, Watt IA: Supporting consumer involvement in decision-making: what constitutes quality in consumer health information? Int J Qual Health Care. 1996;8:425-37.

9. Hankinson, Hobsley M, Wood PJ: Medical negligence in Surgery. Indian J Surg. 1990;34:321-3.

10. Mysore V: Standard guidelines of care for dermatosurgical procedures. Indian J Dermatol Venereol Leprol 2008;74:392-3

11. Cobbalt JR, Lippins W, Southwood RL: Medical Negligence in Plastic Surgery. Indian J Plast Surg. 1990;33:517-24.

12. Shruti P: Hypocrites' oath? The Pioneer on Sunday, New Delhi, 17 December 1995 p 5.

13. Gillon R: Medical ethics: Four principles plus attention to scope. BMJ. 1994;30:184-8.

14. Putta S: IADVL book on medical ethics and consumer protection act. 1st ed. Indian Association of Dermatologists, Venereologists and Leprologists, 2007.

\footnotetext{
Copyright by Neerja Puri, et al. This is an open access article distributed under the terms of the Creative Commons Attribution License, which per-
} mits unrestricted use, distribution, and reproduction in any medium, provided the original author and source are credited. 